\title{
Análise da Participação Feminina nos Cursos de Licenciatura em Computação e Sistemas de Informação
}

\author{
Niellen N. M. de Souza ${ }^{1}$, Ana Carina G. de Lima ${ }^{1}$, \\ Decíola F. de Sousa ${ }^{1}$ \\ ${ }^{1}$ Instituto Ciberespacial - Universidade Federal Rural da Amazônia(UFRA) \\ Avenida Presidente Tancredo Neves, 2501 - Belém-Pará \\ \{aninhaufra, menescalniellen\}@gmail.com, deciola.sousa@ufra.edu.br
}

\begin{abstract}
Women have been essential in building the history of computing. However, most of the accomplishments were excluded throughout history. Although female participation and enrollment of women in courses related to technology has increased in recent years, when compared, it is observed that the number of females is definitely below the number of male participants in the field. This article aims to open a brief discussion about the participation of women in society and to make a statistical analysis of the number of women who are entering the Computing and Information System degree courses.
\end{abstract}

Resumo. As mulheres foram essenciais na construção da história da computação, no entanto foram ao longo do processo excluídas dos relatos históricos. Apesar da participação feminina na sociedade ter aumentado nos últimos anos, assim como número de matrículas de mulheres nos cursos relacionados a áreas da tecnologia, ainda se observa que o número está abaixo da média de ingressantes homens, quando comparado. Este artigo visa abrir uma breve discussão sobre a participação das mulheres na sociedade e fazer uma análise estatística do número de mulheres que estão ingressando nos cursos de Licenciatura em Computação e Sistemas de Informação.

\section{Introdução}

As mulheres sempre estiveram presentes na construção científica das tecnologias, da computação, da matemática e engenharias, mas foram apagadas dos registros históricos, dos relatos e da história da ciência. Mulheres como Ada Lovelace, reconhecida mundialmente como a criadora do primeiro programa de computador da história, até pouco tempo permaneciam num quase anonimato. Tinham seus feitos questionados e praticamente desacreditados pelos grandes escritores.

Quem é mulher na área de Tecnologia da Informação (TI), sabe da obviedade de que não existe diferença em termos de potenciais e capacidades intelectuais apenas por questão de gênero. Existem bons e maus profissionais e para isso não importa o gênero. Uma mulher pode ser femininamente inteligente e competente na área de informática. Um homem pode não se sair tão bem assim [Oliveira et al. 2016].

Importantes avanços estão sendo feitos para a inclusão de mulheres na computação, o próprio evento do Women in Information Technology (WIT) ${ }^{1}$ é um deles, pois o evento abre um indispensável espaço para discussões nas questões de gênero,

\footnotetext{
${ }^{1}$ Evento organizado anualmente pelo Congresso da Sociedade Brasileira da Computação.
} 
permite também o acesso a informações das construções históricas que a mulher tem feito durante sua trajetória, além de reforçar a busca pela equidade de oportunidades.

Este trabalho visa demonstrar de forma resumida o ingresso e a participação das mulheres no curso de Licenciatura em Computação e Bacharelado em Sistemas de Informação, na Universidade Federal Rural da Amazônia (UFRA) na cidade de Belém do Pará. No que se concentra o desenvolvimento desse trabalho, o mesmo segue organizado da seguinte forma: apresentamos na Seção 2 sobre mulheres na computação e na sociedade; na Seção 3 sobre o quantitativo da participação de mulheres na computação, na Seção 4 os resultados dos dados analisados na seção anterior; por fim, na Seção 5 as nossas considerações finais.

\section{Mulheres na Sociedade e na Computação}

Apesar do número de mulheres nas universidades ser crescente, observou-se que elas escolhiam predominantemente áreas relacionadas à educação, saúde, artes e não as engenharias, matemáticas e também, nosso objeto de estudo, a computação. O mais preocupante, segundo [Velho et al. 2012] é que as mulheres quando não escolhem as áreas de exatas o fazem de forma inconsciente, e este ainda é um problema recorrente. Para as autoras isto é um problema que vem das escolas, das etapas primárias do ensino, onde os meninos são incentivados a gostar de matemática e física e as meninas não.

Para que estas mulheres possam ser atuantes no mercado de trabalho, promovendo a igualdade social, é necessário que seja garantido o acesso e a permanência destas nas universidades, principalmente nos cursos relacionados a área da computação. $\mathrm{O}$ relatório com dados do Censo 2015, cedido pelo INEP e SBC ${ }^{2}$, demonstra que no cenário nacional é possível observar que a entrada destas mulheres nas universidades (nos cursos de Computação e afins) foi mais significativa nos últimos 8 anos, mas o número de concluintes ainda permanece abaixo da média.

Embora pareça animador o número de mulheres ter crescido no mercado de trabalho, nas universidades e até mesmo na política, este ainda é um fator novo para a sociedade que precisa compreender o papel da mulher e compreender que seu potencial é idêntico ao masculino [Oliveira et al. 2016].

\section{Quantitativo da Participação Feminina em Computação}

Os cursos noturnos da Universidade Federal Rural da Amazônia (UFRA), Campus Sede em Belém do Pará, são Licenciatura em Computação e Bacharelado em Sistemas de Informações, sendo estes criados em 2009. Como relatado na Seção 2, a participação feminina no curso de computação possui um percentual baixo, o índice é ainda menor quando concluem o curso.

A fim de discutir sobre o assunto em relação a esta Universidade, nesta seção será apresentado um levantamento sobre a quantidade de ingressantes e formandos (Seção 3.1) e o questionário sobre a participação feminina nos cursos de computação (Seção 3.2).

\footnotetext{
${ }^{2}$ Disponível em: http://www.sbc.org.br/documentos-da-sbc/summary/133-estatisticas/1074-educacaosuperior-em-computacao-estatisticas-2015
} 


\subsection{Quantidade de Ingressantes e Formados}

Este estudo foi realizado a partir dos dados obtidos na relação de discentes dos dois cursos de TI da UFRA, o objetivo foi realizar o levantamento da quantidade de ingressantes e formados nesta área.

Os dados foram coletados do Sistema Integrado de Gestão de Atividades Acadêmicas (SIGAA) e organizados nas seguintes tabelas: na Tabela 1 é demonstrado o quantitativo de Ingressantes de 2009 a 2016 e na Tabela 2 o quantitativo de formandos de 2013 a 2016, dos cursos de Licenciatura em Computação e Bacharelado em Sistemas de Informações.

Tabela 1. Ingressantes dos Cursos de TI da UFRA

\begin{tabular}{|c|c|c|c|c|c|c|c|c|c|}
\hline & $\mathbf{2 0 0 9}$ & $\mathbf{2 0 1 0}$ & $\mathbf{2 0 1 1}$ & $\mathbf{2 0 1 2}$ & $\mathbf{2 0 1 3}$ & $\mathbf{2 0 1 4}$ & $\mathbf{2 0 1 5}$ & $\mathbf{2 0 1 6}$ & Total \\
\hline LC - Mulheres & 16 & 24 & 16 & 10 & 17 & 16 & 10 & 5 & $\mathbf{1 1 4}$ \\
\hline LC - Homens & 32 & 26 & 34 & 37 & 32 & 40 & 44 & 42 & 287 \\
\hline BSI - Mulheres & 9 & 17 & 14 & 8 & 12 & 15 & 5 & 6 & $\mathbf{8 6}$ \\
\hline BSI - Homens & 39 & 31 & 35 & 42 & 38 & 43 & 49 & 41 & 318 \\
\hline
\end{tabular}

Tabela 2. Formados dos Cursos de TI da UFRA

\begin{tabular}{|c|c|c|c|c|c|}
\hline & $\mathbf{2 0 1 3}$ & $\mathbf{2 0 1 4}$ & $\mathbf{2 0 1 5}$ & $\mathbf{2 0 1 6}$ & Total \\
\hline LC - Mulheres & 13 & 12 & 2 & 1 & $\mathbf{2 8}$ \\
\hline LC - Homens & 17 & 15 & 8 & 4 & 44 \\
\hline BSI - Mulheres & 5 & 5 & 4 & 13 & $\mathbf{2 7}$ \\
\hline BSI - Homens & 9 & 8 & 20 & 12 & 49 \\
\hline
\end{tabular}

\subsection{Questionário de Participação Feminina}

O questionário foi aplicado para analisar a participação de mulheres nos cursos de computação, sendo este repassado para 45 discentes das 8 turmas ativas de 2013 a 2016. O objetivo era fazer o levantamento de informações essenciais para análise de escolha de curso, motivações, estágios, preconceito, dentre outros assuntos da mesma relavância.

\section{Resultados}

Nos cursos de TI da UFRA, o número de ingressantes do sexo masculino é superior ao de mulheres, sendo o número de discentes mulheres maior em Licenciatura em Computação (Tabela 1). Já o número de formados tem uma quantidade quase idêntica para os dois gêneros, mesmo assim o número de mulheres formandas é menor (Tabela 2). Um fator animador a ser observado é que a quantidade de ingressantes mulheres nos cursos é quase proporcional ao de formadas, o que pode demonstrar que estas mulheres estão ingressando e conseguindo ter condições de concluir o curso. Desmonstra também o quanto o cenário tem mudado para as mulheres, quanto veem ocupando os espaços na universidade.

Em Licenciatura em Computação (LC), 27 discentes responderam o questionário, já em Bacharelado em Sistemas de Informação (BSI), com o público respondente menor, apenas 18 discentes responderam. Analisando os dois cursos, percebemos que 13,33\% de 
alunas pertencem a turmas anteriores a 2013, das turmas de 2013 e 2014 a quantidade de mulheres é superior em comparação as outras turmas.

Destacamos alguns pontos importantes para a nossa análise, de modo geral, $57,78 \%$ afirmaram que o curso foi escolhido como primeira opção. Em todas as turmas de LC, a faixa etária é superior a 19, com exceção da turma de 2016, composta apenas por alunas de idade superior a 30. Já em BSI, a faixa etária é diferente, em 2013, todas estão na faixa de 22 a 25 anos, nas demais turmas a faixa etária é superior a 19. As alunas de LC, entre 19 a 25 anos, são na maioria solteiras e sem filhos, acima de 26 anos, são solteiras, casadas ou possuem outro tipo de estado civil, dentre essas, apenas 8 mulheres têm de 1 a 2 filhos. Em BSI, a maioria são solteiras e 8 têm 1 ou 3 filhos.

Sobre se há algo que possa atrapalhar a formação no curso, obtivemos $46,67 \%$ de respostas "Sim", os principais motivos foram: greve, disciplinas pendentes, dificuldade nas disciplinas de programação, dificuldade em conseguir estágio, Trabalho de Conclusão de Curso (TCC) incompleto, trabalho, problemas pessoais e preconceito. Inclusive, $53,33 \%$ das discentes de LC e BSI confirmaram ter sofrido algum tipo de preconceito por ter optado esta área (Figura 1).

Destacamos nesta pesquisa, a quantidade de mulheres que trabalham e/ou estagiam. Em LC, apenas 13 trabalham em diferentes áreas (saúde, TI, educação e área financeira), de 14 mulheres que não trabalham, 9 fazem estágio em diversas áreas de TI. Em BSI, 12 trabalham em diversas áreas (vendas, saúde, TI, administração, educação), de 6 mulheres que não trabalham, todas fazem estágio em áreas de TI. Dentre as mulheres que trabalham, a maioria delas fazem estágio em Manutenção e Suporte de Computadores. De modo geral, as alunas estagiam na área de TI, principalmente em Manutenção e Suporte de Computadores.

Sobre a participação em um ou mais Programas de Extensão e/ou Ensino ofertados pela Universidade, de 27 discentes de LC, 21 participam do PIBID, 6 do Sementes Digitais, os dois programas são voltados ao ensino de Computação, já em BSI, apenas uma aluna participou de algum dos Programas. Quanto a composição e aprovação de artigos, apenas uma discente de LC teve artigo aprovado, e 2 alunas de BSI escreveram artigos, mais apenas de uma foi aprovado. O número parcial de mulheres de LC e BSI, fizeram algum curso para formação complementar, sendo principalmente voltado para Programação e Manutenção e Suporte de Computadores. 92,59\% das discentes de LC têm interesse em estudar uma pós-graduação, enquanto que as de BSI, todas pretendem estudar ao completar a graduação.

De acordo com a Figura 1, de modo geral, 57,78\% das mulheres tinham os cursos de TI como primeiras opções de escolha para ingresso na universidade, que demonstra que elas tinham interesse em ingressar nesta área, embora ainda seja um número pequeno dentro de um universo de $100 \%$. Quando questionadas sobre existência de fatores que as pudessem impedir de continuar o curso, 46,67\% delas acreditam haver inúmeros. Como os cursos são noturnos surgiu então a necessidade de questionar se estas mulheres já estão inseridas no mercado de trabalho, mesmo que não seja o da área em que estudam, e $55,56 \%$ respondeu que "Sim". Já quanto ao estágios, 64,44\% respondeu que estagia na área de TI, este número é muito animador, pois estas mulheres estão tendo a oportunidade de obter alguma experiência no mercado de trabalho de TI, aumentando inclusive a 
representatividade de mulheres na área.

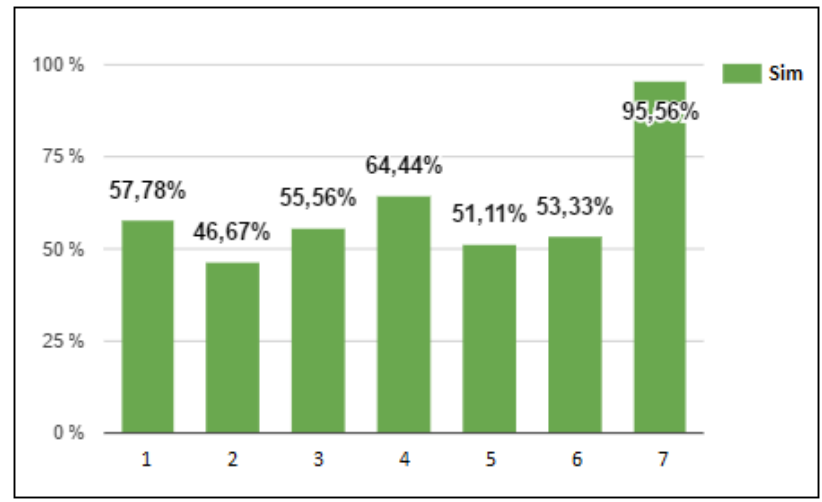

Figura 1. Principais resultados do questionário

Quando perguntadas sobre participação em programas de ensino e/ou extensão, o número foi de $51,11 \%$, o que é positivo porque mais da metade estão conseguindo ter acesso a estes programas. Quando questionadas sobre um problema que é muito comum na área de TI, o preconceito, 53,33\% respondeu que já sofreu. Um número muito animador foi o interesse de fazer alguma pós-graduação, este número foi de $95,56 \%$ das mulheres.

\section{Considerações Finais}

O artigo apresentou uma análise da participação das mulheres em dois cursos da área de TI de uma Universidade. A pesquisa possibilitou conhecer o perfil das discentes em ambos os cursos e a diferença na escolha do curso. Evidenciando que a Licenciatura atrai mais mulheres que o curso de Bacharelado. Percebeu-se que a participação das mulheres nos dois cursos vem diminuindo, o que é preocupante, incentivando o investimento em políticas públicas para motivar a participação feminina em curso superior na área de TI.

Os desafios para as mulheres na área de TI são grandes, porém motivantes, pois a maioria pretende continuar os estudos através de uma pós-graduação. O que entristece é que poucas tentaram escrever artigos científicos durante a graduação. O Women in Information Technology (WIT) é uma excelente oportunidade para se discutir e analisar a participação das mulheres na área de TI. Como trabalho futuro, pretende-se analisar a participação das discentes graduadas dos dois cursos da Instituição no mercado de trabalho.

\section{Referências}

Oliveira, A. C., Oliveira, K., Alves, E., Tassyany, M., Cabral, Y., Sousa, T., and Batista, F. (2016). Você é o melhor menino desse grupo! In Anais do X WIT Women in Information Technology.

Velho, L., León, E., et al. (2012). A construção social da produção científica por mulheres. cadernos pagu. 